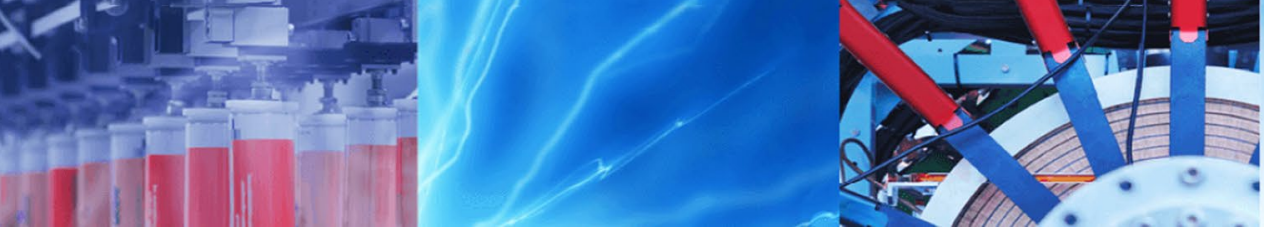

Research Article

\title{
Structure and morphology of composite coating of chromium with diamond nanoparticles on sintered steels
}

\author{
Vladimir Petkov ${ }^{1} \cdot$ Radoslav Valov $^{1}$ iD
}

Received: 1 July 2019 / Accepted: 1 November 2019 / Published online: 5 November 2019

(c) Springer Nature Switzerland AG 2019

\begin{abstract}
Electrochemical chromium coatings modified with diamond nanoparticles (ND) were deposited on sintered steel materials obtained from iron powder and ultrafine graphite powder. The diamond nanoparticles were produced by detonation synthesis. Their average size is $6 \mathrm{~nm}$. The sintered steel consisted of $0.2,0.4,0.6$ and $0.8 \% C$ (added in the form of graphite) by weight. The produced composite coatings consisting of $\mathrm{Cr}+\mathrm{ND}$ were compact, tightly adhering to the substrate, with thickness of about 25-35 $\mu \mathrm{m}$. The surface morphology and microstructure of the coatings were investigated by SEM and EDS analyzes. The main objective of the study was to explore the presence of ND in the coating by the X-ray photoelectron spectroscopy and the impact of the ND concentration in the electrolyte on the presence of the diamond nanoparticles in the coating. The spectra of the $C 1 s$ photoelectronic line were obtained, the $s p^{3} / s p^{2}$ ratio and the $s p^{3}+s p^{2}$ sum were determined electronically on the surface of the coatings (depth $10 \mathrm{~nm}$ ). The $\mathrm{Cr} 2 \mathrm{p}$ photoelectronic line spectra were also obtained. The coatings were deposited from electrolytes with ND concentrations of 10,25 and $40 \mathrm{~g} / \mathrm{l}$. A diamond-like phase has been found in coatings obtained at concentrations of diamond nanoparticles in the electrolyte of 25 and $40 \mathrm{~g} / \mathrm{l}$. The $s \mathrm{~s}^{3} / s p^{2}$ ratio with a value equal to or greater than 1.2 is an indication of the presence of a diamond-like phase in the coatings and the ratio depends on the concentration of ND in the electrolyte.
\end{abstract}

Keywords Diamond nanoparticles · Sintered steel · X-ray photoelectron spectroscopy (XPS) · Electrochemical chromium coating

\section{Introduction}

The electrochemical chromium coatings, modified with diamond nanoparticles, deposited on wrought steel, sintered steel and other metals and alloys increase several times their hardness, wear and corrosion resistance in comparison to the monochromium coatings. Our studies unambiguously showed the influence of the diamond nanoparticles in improvement of the chemical and mechanical properties of the composite $\mathrm{Cr}+\mathrm{ND}$ coatings [1-3]. The role of the diamond nanoparticles in the built-up of the coatings and their presence in the layer are controversial. The ND added to the electrolyte were obtained by detonation synthesis. According to [4] the obtained product may contain up to $80 \%$ of nanoparticles. They are cleaned from soot and other by-products by a series of oxidation-reduction and thermal processes. ND have a high adsorbtion capacity of different ions and functional groups due to their high specific surface area of about $300-450 \mathrm{~m}^{2} / \mathrm{g}[5]$.

The goal of our research was to ascertain the presence of the diamond nanoparticles in the electrodeposited composite coating by the X-ray photoelectron spectroscopy.

Vladimir Petkov, radoslav.valov@gmail.com | ${ }^{1}$ Institute of Metal Science, Equipment and Technologies - BAS, 67 Shipchenski Prohod Blvd, 1574 Sofia, Bulgaria. 


\section{Experimental}

The steel samples were prepared of pure iron powder NC 100-24 (Höganäs $A B$ ) and ultrafine graphite C-UF (Höganäs $A B$ ). The carbon content (in the form of graphite) in sintered steels was $0.2,0.4,0.6$ and $0.8 \mathrm{wt} \%$ respectively. The samples were compacted at $660 \mathrm{MPa}$ and sintered at $1250{ }^{\circ} \mathrm{C}$ in protective gas mixture consisting of $95 \% \mathrm{~N}_{2}-5 \% \mathrm{H}_{2}$. Following sintering, the electrolytic process was employed to obtained composite coatings. The chromium electrolyte had the following composition: $\mathrm{CrO}_{3}-220 \mathrm{~g} / \mathrm{l}, \mathrm{H}_{2} \mathrm{SO}_{4}-2.20 \mathrm{~g} / \mathrm{l}$. The anode was lead. The diamond nanoparticles were produced by detonation synthesis in NDDS Production Unit at the Altai Research Institute, Russia. The diamond nanoparticles were added to the electrolyte as an aqueous suspension at concentrations of 10, 25 and $40 \mathrm{~g} / \mathrm{l}$. The electrochemical deposition for all samples was carried out at equal current density of $45 \mathrm{~A} / \mathrm{dm}^{2}$ and duration of $45 \mathrm{~min}$.

Surface morphology was investigated using an image of secondary electrons (SEI) with scanning electron microscope JEOL 6390 and INCA Oxford solid-state detector for the characteristic $\mathrm{X}$-ray radiation. The accelerating voltage was $20 \mathrm{kV}$.

$\mathrm{X}$-ray photoelectron analysis was performed by an AXIS Supra electron spectrometer with monochromatic Al radiation of $1486.6 \mathrm{eV}$. Each analysis begins with a full spectrum in an energy range of $0-1200 \mathrm{eV}$ with a transmitting energy of $160 \mathrm{eV}$ and a step of $1 \mathrm{eV}$. After a detailed analysis of the spectrum, the characteristic lines of the surface components were selected for analysis. The narrow slits are scanned at transmitting energy of $20 \mathrm{eV}$ with step $0.1 \mathrm{eV}$.

The analyses were conducted at the $90^{\circ}$ take-off angle, allowing maximum $\mathrm{X}$-ray penetration into the sample, respectively the depth from which the elemental composition information was obtained was not greater than $10 \mathrm{~nm}$. In this way the spectra of $\mathrm{C} 1 s, \mathrm{O} 1 \mathrm{~s}, \mathrm{Cr} 2 p$, $\mathrm{N} 1 s, \mathrm{Na} 1 s$ were recorded. The resulting spectra were subjected to further processing, such as surface concentration calculations and deconvolution. The deconvolution of $\mathrm{C} 1 \mathrm{~s}$ and $\mathrm{Cr} 2 \mathrm{p}$ spectra was performed using specialized software XPS PEAK 4.1.

\section{Results and discusion}

The morphology of the composite chromium coating on sintered steel containing $0.2 \mathrm{wt} \% \mathrm{C}$ is shown in Fig. 1. The slightly folded and fine-grained structure of the coating

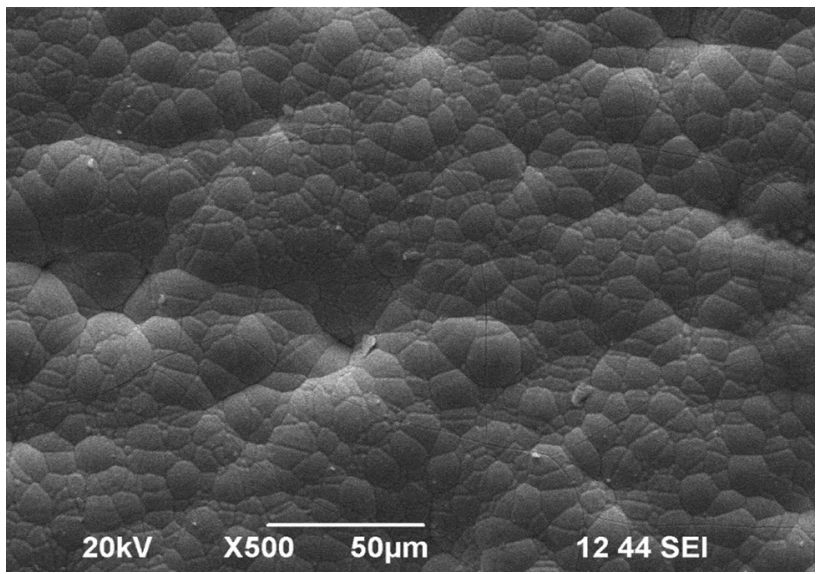

Fig. 1 Surface morphology of chromium composite coating with diamond nanoparticles on sintered $\mathrm{Fe}-0.2 \% \mathrm{C}$ steel, obtained from electrolyte with $25 \mathrm{~g} / \mathrm{l}$ diamond nanoparticles concentration

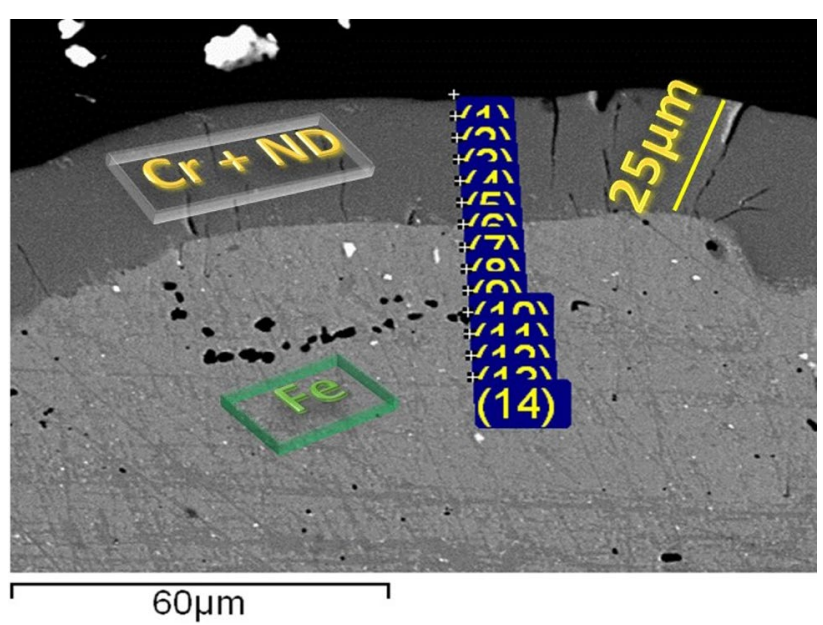

Fig. 2 Microstructure of composite $\mathrm{Cr}+\mathrm{ND}$ coating on sintered Fe$0.2 \% \mathrm{C}$ steel showing the points of the SEM-EDS analysis

surface is clearly observed. The coating follows the surface of the sintered sample.

Scaning Electron Microscopy-Energy Dispersive Spectroscopy (SEM-EDS) analysis of the cross section of chromium composite coating with diamond nanoparticles on sintered steel was performed. The coating was obtained from electrolyte with $25 \mathrm{~g} / \mathrm{l}$ concentration of diamond nanoparticles. It was deposited on sintered $\mathrm{Fe}-0.2 \% \mathrm{C}$ steel. The analysis was made along a line at 14 points with $5 \mu \mathrm{m}$ between them in the coating and the matrix (Fig. 2). The obtained coating was compact, well adhering to the matrix, with thickness of about $30 \mu \mathrm{m}$.

Changes in the amount of $\mathrm{Cr}$ and $\mathrm{Fe}$ in atomic \% along the investigated line are shown in Fig. 3. The coating is monolithic and has a constant $100 \%$ chromium content. 


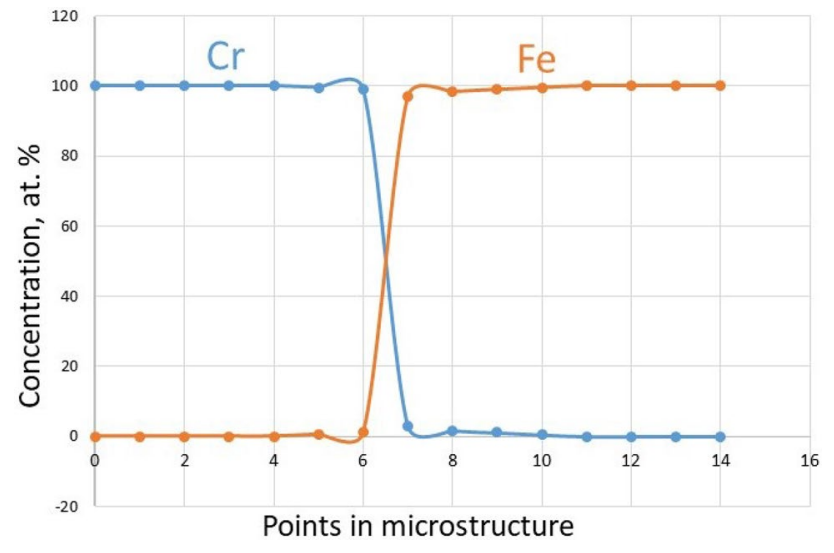

Fig. 3 SEM-EDS analysis of the chromium and iron content in the cross section of composite chromium coating with diamond nanoparticles, electrolyte containing $25 \mathrm{~g} / \mathrm{l} \mathrm{ND}$, sintered Fe- $0.2 \% \mathrm{C}$ steel

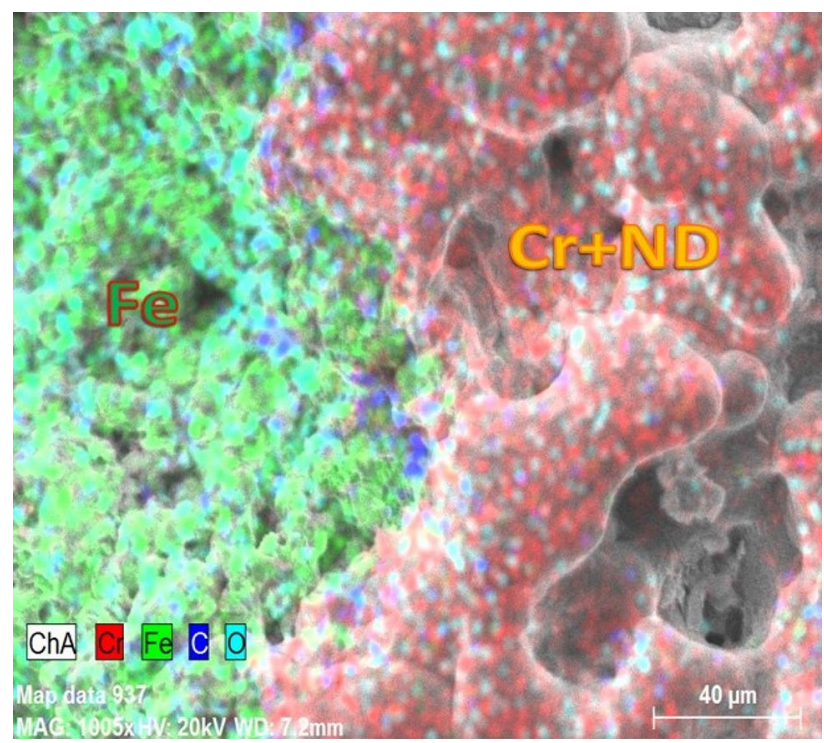

Fig. 4 Microanalysis of the fracture of $\mathrm{Fe}-0.2 \% \mathrm{C}$ steel along the boundary of the coating and the steel matrix, $\mathrm{Cr}$-red, $\mathrm{Fe}-$ green, C-blue

The coating is from point 0 to point 6 which corresponds to $30 \mu \mathrm{m}$ thickness. From point 7 to point 14 in the matrix is $100 \%$ iron. The smooth change of the $\mathrm{Cr}$ and Fe concentration at the matrix-coating boundary (point 6-point 7) shows the diffusion character of the interaction between the two metals.

The microanalysis of the fracture of the matrix and the chromium layer is shown in Fig. 4. The coating was obtained from electrolyte with $25 \mathrm{~g} / \mathrm{l}$ concentration of ND. It was deposited on sintered $\mathrm{Fe}-0.2 \% \mathrm{C}$ steel. The chromium coating deposited on the sintered steel follows its surface. The electrodeposited chromium fills part of the pores in depth and width of the matrix. This process is in

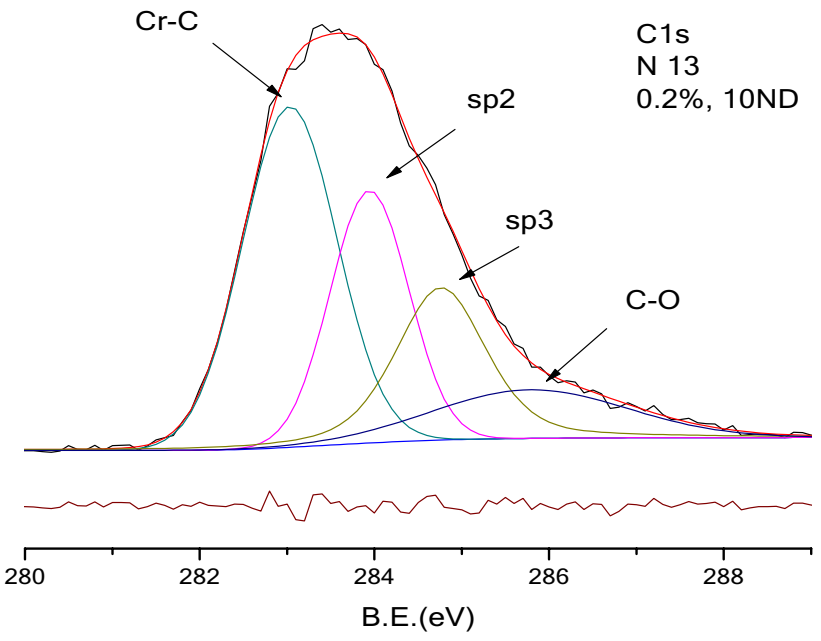

Fig. 5 Spectrum of $\mathrm{C} 1 \mathrm{~s}$ photoelectron line of composite $\mathrm{Cr}+\mathrm{ND}$ coating (after deconvolution). Diamond nanoparticles concentration in the electrolyte $10 \mathrm{~g} / \mathrm{l}$

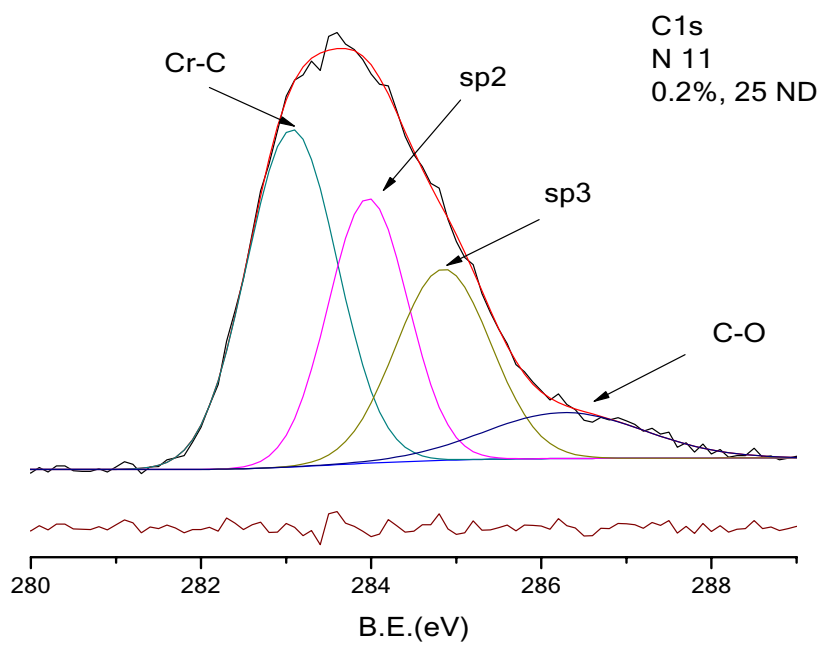

Fig. 6 Spectrum of $\mathrm{C} 1 \mathrm{~s}$ photoelectron line of composite $\mathrm{Cr}+\mathrm{ND}$ coating (after deconvolution). Diamond nanoparticles concentration in the electrolyte $25 \mathrm{~g} / \mathrm{l}$

direct relation to the concentration of the diamond nanoparticles in the electrolyte and the duration of the process according to our previous investigations [3]. The fracture microanalysis definitely shows that there is only chromium on the surface; In the matrix mainly iron and very small amount of carbon was observed. Most probably this carbon comes from the sintered steel.

The electron structure of the diamond nanoparticles consists of $s p^{2}$ and hybridized $s p^{3}$ groups [5]. The spectra of the $\mathrm{C} 1 s$ photoelectron line of the coatings on sintered steels with $0.2 \mathrm{wt} \% \mathrm{C}$ electrodeposited from electrolytes with ND concentration of 10,25 and $40 \mathrm{~g} / \mathrm{l}$, respectively, 


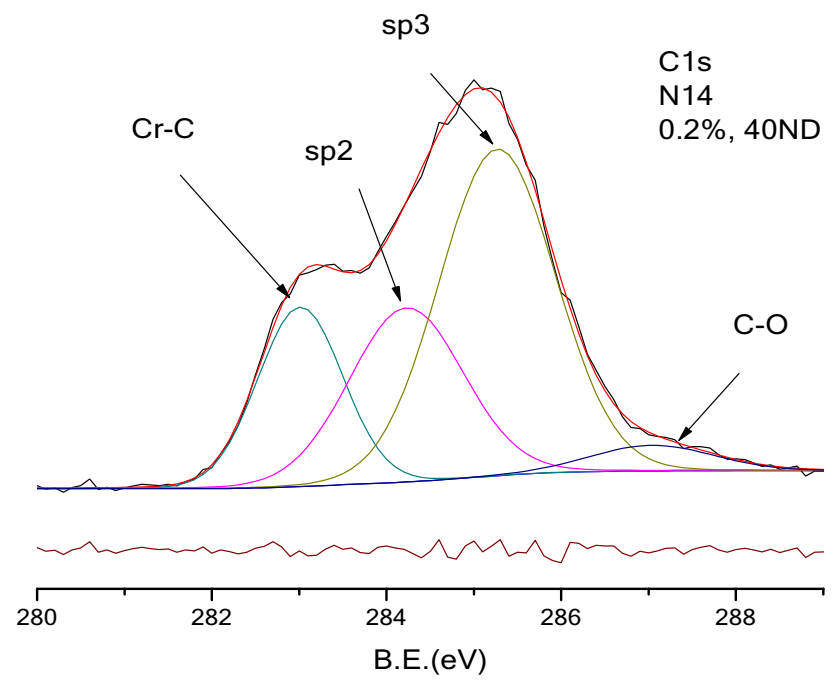

Fig. 7 Spectrum of $\mathrm{C} 1 \mathrm{~s}$ photoelectron line of composite $\mathrm{Cr}+\mathrm{ND}$ coating (after deconvolution). Diamond nanoparticles concentration in the electrolyte $40 \mathrm{~g} / \mathrm{l}$

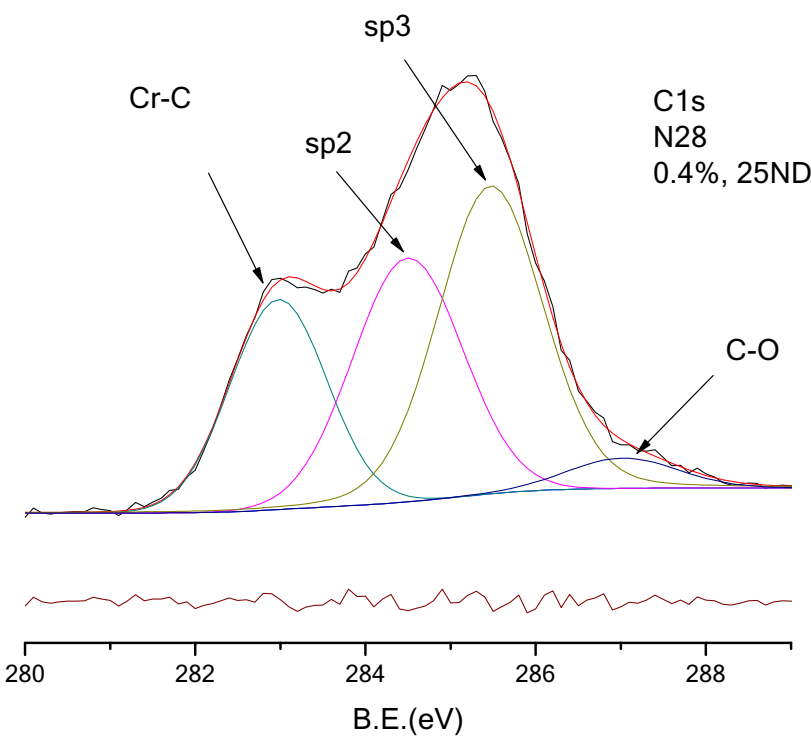

Fig. 8 Spectrum of $\mathrm{C} 1 \mathrm{~s}$ photoelectron line of composite $\mathrm{Cr}+\mathrm{ND}$ coating (after deconvolution) electrodeposited on $\mathrm{Fe}-0.4 \% \mathrm{C}$ sintered steel

after deconvolution, are presented in Figs. 5, 6 and 7. The spectra of the carbon line (C1s) consists of 4 peaks, associated with $\mathrm{Cr}-\mathrm{C}, s p^{2}, s p^{3}, \mathrm{C}-\mathrm{O}$ bonds with binding energies $283 \mathrm{eV}, 284.4 \mathrm{eV}, 285.3 \mathrm{eV}$ and $286.5 \mathrm{eV}$, respectively [6].

The spectra of the C1s photoelectron line of the composite $\mathrm{Cr}+\mathrm{ND}$ coatings electrodeposited from electrolytes with diamond nanoparticles concentration of $25 \mathrm{~g} / \mathrm{l}$ on sintered steels containing $0.4,0.6$ and $0.8 \mathrm{wt} \% \mathrm{C}$, respectively, after deconvolution, are presented in Figs. 8, 9 and 10.

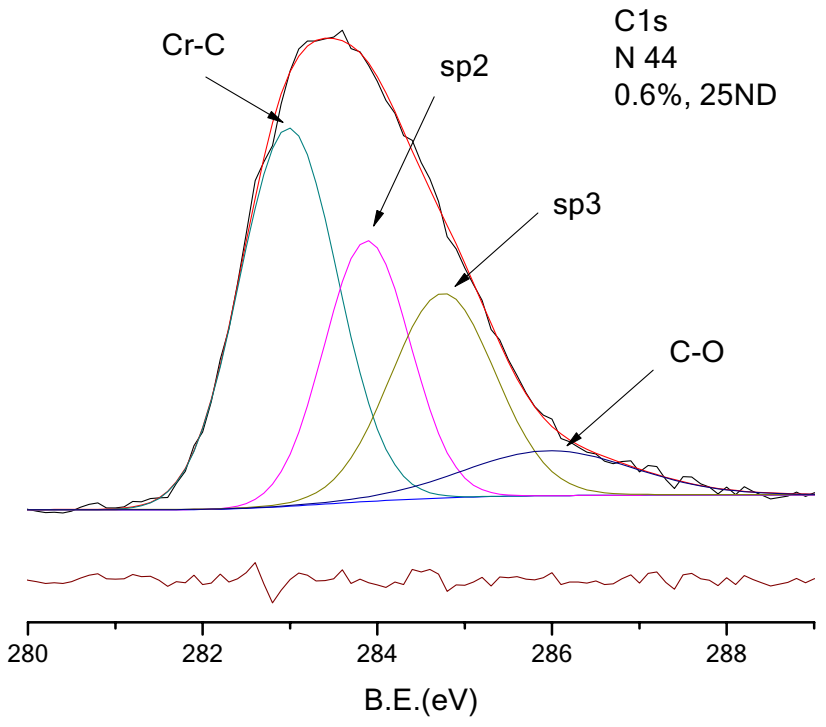

Fig. 9 Spectrum of $\mathrm{C} 1 \mathrm{~s}$ photoelectron line of composite $\mathrm{Cr}+\mathrm{ND}$ coating (after deconvolution) electrodeposited on $\mathrm{Fe}-0.6 \% \mathrm{C}$ sintered steel

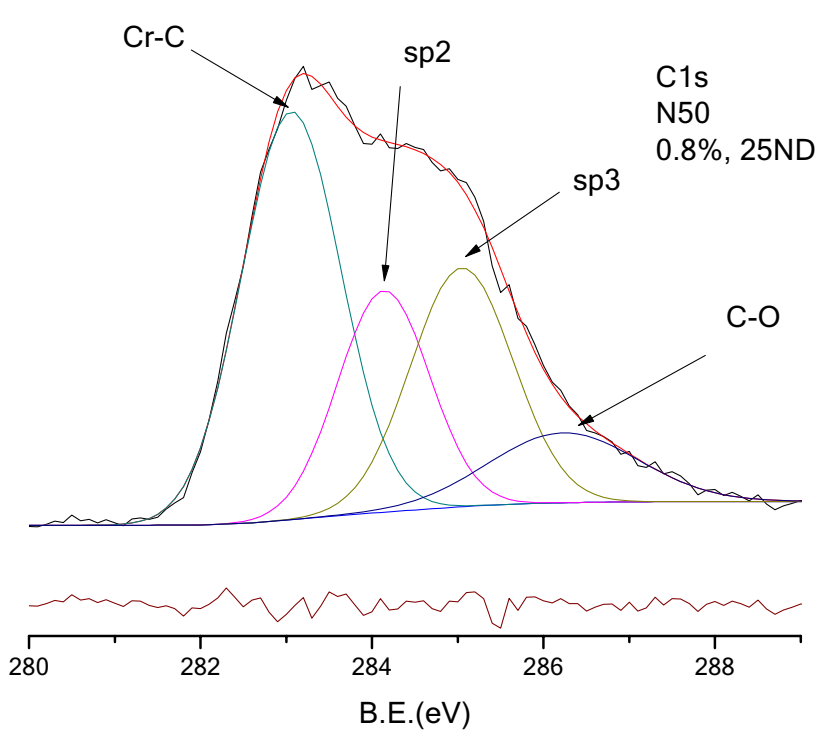

Fig. 10 Spectrum of $\mathrm{C} 1 s$ photoelectron line of composite $\mathrm{Cr}+\mathrm{ND}$ coating (after deconvolution) electrodeposited on $\mathrm{Fe}-0.8 \% \mathrm{C}$ sintered steel

The calculations of $s p^{3} / s p^{2}$ ratio, the sum of $s p^{3}$ and $s p^{2}$ and the value of $\mathrm{Cr}-\mathrm{C}$ bond of samples obtained from electrolyte with different ND concentration and samples with different graphite content in the steel matrix are presented in Table 1.

The $s p^{3} / s p^{2}$ ratio of 1.2 and above is typical for the diamond-like phase. It can be seen from the data presented in the Table 1 that in the coatings electroplated from electrolyte with ND concentration 25 and $40 \mathrm{~g} / \mathrm{l}$ 
Table 1 The values of the bonds in the spectra of the composite $\mathrm{Cr}+\mathrm{ND}$ coating in relation with the graphite content in the steel matrix and the concentration of the ND in the electrolyte

\begin{tabular}{lllll}
\hline $\begin{array}{l}\text { Graphite content in } \\
\text { steel matrix (wt\%) }\end{array}$ & $\begin{array}{l}\text { Concentration of ND in } \\
\text { the electrolyte }(\mathrm{g} / \mathrm{l})\end{array}$ & $s p^{3} / s p^{2}$ (ratio) & $s p^{3}+s p^{2}$ (sum) & $\mathrm{Cr}-\mathrm{C}$ bond (\%) \\
\hline 0.2 & 10 & 0.81 & 46.32 & 41.43 \\
0.2 & 25 & 0.86 & 50.96 & 39.57 \\
0.2 & 40 & 1.89 & 75.99 & 19.98 \\
0.4 & 25 & 1.27 & 72.04 & 24.13 \\
0.6 & 25 & 0.97 & 49.67 & 41.57 \\
0.8 & 25 & 1.2 & 46.7 & 42.43 \\
\hline
\end{tabular}

\section{Conclusions}

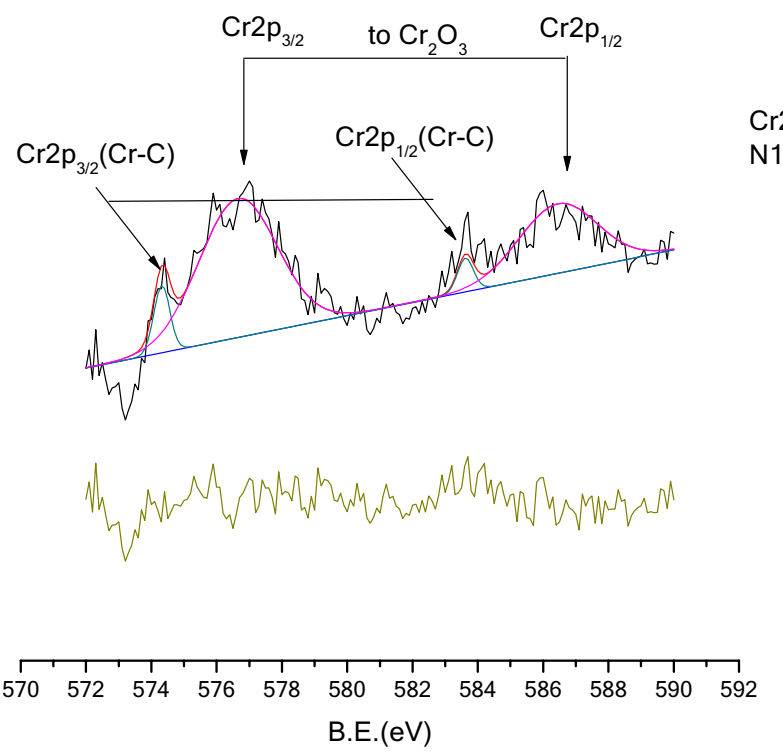

Fig. 11 Spectrum of $\mathrm{Cr} 2 \mathrm{p}$ photoelectron line of composite $\mathrm{Cr}+\mathrm{ND}$ coating (after deconvolution) electrodeposited on $\mathrm{Fe}-0.2 \% \mathrm{C}$ sintered steel. Diamond nanoparticles concentration in the electrolyte $25 \mathrm{~g} / \mathrm{l}$

the ratio $s p^{3} / s p^{2}$ has a value equal or over 1.2. For this reason the authors assumed that it was possible nanodiamonds to be present in the surface layer of the these coatings.

The Cr2p spectrum (after deconvolution) of a sample prepared from electrolyte with diamond nanoparticles concentration $25 \mathrm{~g} / \mathrm{l}$ is shown in Fig. 11. Cr2p binding energy is $574.2 \mathrm{eV}$ and $576.6 \mathrm{eV}$, whereby it is possible to attract nanodiamond particle to the chromium ions (atoms). The presence of $\mathrm{Cr}_{2} \mathrm{O}_{3}$ lines is probably due to the air oxidation of the $\mathrm{Cr}$ coating after its production. The photoelectron line $\mathrm{Cr} 2 \mathrm{p}_{3 / 2}$ corresponds to the carbide bond $\mathrm{Cr}-\mathrm{C}(574.2 \mathrm{eV})$ and respectively to the chemical compound $\mathrm{Cr}_{3} \mathrm{C}_{7}$ [7]. The question whether it is possible to obtain chromium carbide at nano level remains open for further research.
- It has been found that the composite chromium coating with diamond nanoparticles was characterised by fine-grained microcrystalline structure. The coating on the surface of the sintered Fe-? \%C steel, was dense and well adhering to the matrix.

- It has been found by XPS that it is possible diamond nanoparticles to be incorporated into the surface structure of the electrochemically deposited composite coating on sintered steel.

- It has been found that ratio $s p^{3} / s p^{2}$ with value equal or over 1.2, which is an indication of the presence of a diamond-like phase in the coatings, depends on the concentration of ND in the electrolyte.

- The photoelectron line $\mathrm{Cr} 2 \mathrm{p}_{3 / 2}$ with binding energy $574.2 \mathrm{eV}$ corresponds to the carbide bond $\mathrm{Cr}-\mathrm{C}$, respectively to the chemical compound $\mathrm{Cr}_{3} \mathrm{C}_{7}$.

Acknowledgements The financial support of the Fund "Scientific Researches" at the Ministry of Education and Science, Contract No DN 07/8/15.12.2016 is gratefully acknowledged.

\section{Compliance with ethical standards}

Conflict of interest On behalf of all authors, the corresponding author states that there is no conflict of interest.

\section{References}

1. Gidikova N, Sulowski M, Petkov V, Valov R, Cempura G (2017) Composite coatings of chromium and nanodiamonds particls of steel. Arch Metall Mater 62:3411-3414

2. Gidikova N, Sulowski M, Madej M, Valov R., Petkov V (2017) Mechanical properties of composite coatings of chromium and nanodiamonds on aluminium. In: MATEC-Web of conferences, vol 145, p 05012

3. Gidikova N, Salamci E, Valov R, Petkov V, Unal R (2017) Effect of nanodiamonds modification of chromium coating on sintered ferrous materials. J Mater Sci Technol 25:80-85

4. Krueger A (2008) The structure and reactivity of nanoscale diamond. J Mater Chem 18:1485-1492 
5. Raty JV, Galli G, Bosted C, Bauren TW, Terminello LJ (2003) Quantum confinement and fullerenike surface reconstructions in nanodiamonds. Phys Rev Lett 90:037401

6. Diaz J, Paokicelli G, Rerrer S, Cominn F (1996) Separation of the $s p^{3}$ and $s p^{2}$ components in the C1s photoemission spectra in amorphous carbon films. Phys. Rev, B 54:8064-8069

7. Healy D, Smith C, Rubiano R, Elliot E, Springer W (1994) Use of tetraneopentylchromium as a precursor for the organometallic chemical vapor deposition of chromium carbide: a reinvestigation. Chem Mater 6:448

Publisher's Note Springer Nature remains neutral with regard to jurisdictional claims in published maps and institutional affiliations. 